\section{Vaccines against dengue: a review of current candidate vaccines at advanced development stages}

\author{
Joachim Hombach ${ }^{1}$
}

Key words: dengue, Aedes aegypti, flavivirus, dengue hemorrhagic fever, viral vaccines.

\footnotetext{
World Health Organization, Initiative for Vaccine Research, Geneva, Switzerland. Send correspondence to: Joachim Hombach, e-mail: hombachj@who.int
}

Dengue is a viral disease transmitted by the Aedes aegypti mosquito vector, and is caused by four antigenically related flaviviruses (dengue virus serotypes one through four (DENV-1-4)). Dengue is endemic throughout large parts of the Americas and Asia, and is increasingly reported in Africa. More than 2.5 billion people are at high risk of infection in more than 100 endemic countries throughout the tropical and subtropical climate zones (1). Unplanned urbanization, population migration, and the breakdown of vector control efforts have contributed to the spread of the vector. There is an increase of dengue in its more severe forms, such as dengue hemorrhagic fever (DHF) and dengue shock syndrome (DSS), for reasons that are not fully understood. The severe forms, when not properly treated, have become an increasing cause of morbidity and mortality, and are straining the health care systems of many endemic countries (2). Current treatment of severe disease essentially involves the restoration of fluid, colloid, and electrolyte balances. The disease is mainly observed in children and is a leading cause of pediatric hospitalization. However, in recent years, severe dengue has been increasingly reported in adults as well. Dengue is the most common arthropod-borne disease in humans, and its control represents a high public health priority for many endemic countries.

From a public health perspective, emphasis should be put on the prevention of the disease, which today is essentially confined to vector control measures. Vector control can be successful if implemented in a sustainable and systematic manner. Efforts to develop vaccines began in the 1920s, with inactivated extracts from infected Aedes mosquitoes. During World War II, more systematic studies, using passaged viruses, were undertaken by United States military scientists, including Albert Sabin. The systematic development of a dengue vaccine has been hampered and delayed by the complex pathology of the disease, the need to control four viruses simultaneously, and insufficient investment by vaccine developers, due to low commercial interest. However, over the past few years, the continuing spread and increasing intensity of the disease, combined with new funding mechanisms for the development and use of vaccines for the developing world, have triggered renewed interest and investment in dengue vaccine research. 


\section{DENGUE VACCINE FEASIBILITY}

More than 60 years after the discovery of the virus and the start of systematic research into dengue vaccines, no dengue vaccine has yet been licensed. This situation is in striking contrast to other flavivirus diseases, including yellow fever (YF), Japanese encephalitis (JE), and tick-borne encephalitis, for which effective and safe vaccines have been available for decades. What makes dengue more difficult? Several obstacles have rendered the development and evaluation of dengue vaccines more complicated than that of other flavivirus vaccines.

The disease is caused by four genetically and serologically distinct dengue viruses (DENV-1-4), which cocirculate in many endemic regions and cause complex epidemiologic disease patterns. While infection by one virus/serotype confers lasting protection against reinfection and disease by the same virus/serotype, the same is not true for infection with a heterologous virus/serotype. Worse, heterologous secondary or tertiary infection has been associated with more severe disease, an observation that has led to the development of immune enhancement theories (3).

No suitable animal model exists for dengue, including its severe forms. While monkeys (especially macaques) are susceptible to the virus and represent natural, sylvatic hosts, they only develop moderate viremia and no significant illness, even after secondary infection (4). Genetic markers of viral virulence are not completely understood, hampering rational attenuation approaches for dengue viruses. A direct linkage between viremia in animal models and phenotypic attenuation in humans is also unclear.

Secondary, heterologous dengue infections that appear to involve immune enhancement and lead to severe disease still remain poorly understood. However, nonneutralizing antibodies are believed to contribute to the observed clinical manifestation, and await further analysis (5).

Several implications for the development of a dengue vaccine can be drawn from the above observations. First, a dengue vaccine must be able to protect against all four circulating virus serotypes. Therefore, the vaccine needs to be tetravalent. This effectively requires the development of four monovalent vaccines that subsequently undergo formulation into a tetravalent form. For live vaccines, the tetravalent formulation may be subject to interference phenomena among its individual components. Second, while the monkey model is an important prerequisite to test for neurovirulence, viremia, and immunogenicity, the limitations of the model necessitate extensive screening in human volunteers to initially assess reactogenicity, immunogenicity, and possibly protection, if the human challenge model becomes fully established. Third, while the specific mechanism of immune enhancement remains elusive, and correlates of protection are not yet clearly defined, it is generally accepted that vaccines should elicit tetravalent seroconversion and that neutralizing antibody titers should be persistent. Finally, the clinical evaluation of the vaccine in exposed populations requires careful and longterm follow-up.

\section{DENGUE VACCINE PIPELINE}

The following overview focuses on dengue candidate vaccines that are in advanced stages of development (Table 1). However, it is not intended to provide a full picture of the various strategies and technologies that are currently being investigated at early preclinical development stages.

\section{Live attenuated vaccines}

Several live attenuated candidate vaccines have been developed based on classical virology techniques, mainly using serial passage in primary dog kidney (PDK) cells for attenuation. Two of these candidates have been formulated into tetravalent vaccines and have undergone clinical evaluation (phase 1 and phase 2).

Scientists at Mahidol University (Thailand) developed a candidate tetravalent vaccine, based on passaging human virulent DENV-1, -2 , and -4 in PDK cells, and DENV-3 in primary green monkey kidney (PGMK) cells. Candidate vaccines were tested in Thai volunteers in mono-, bi-, tri-, and tetravalent formulations, and neutralizing titers were observed for up to two years postimmunization (6). Trials were also conducted in the United States, which triggered the reformulation of the DENV-3 component since it interfered with the response to the three other components, resulting in a suppression of the antibody titers. Subsequently, seven different tetravalent formulations were tested in Thai adults.

One tetravalent formulation was selected for an age de-escalating study in 105 flavivirus-naive children in Thailand. For this study, conducted in collaboration with Aventis Pasteur, two doses were scheduled at zero and three to five months, followed by a booster 12 months later. Overall, reactogenicity after the first dose was moderate, although $5 \%$ of children had considerable systemic reactions. Reactogenicity after subsequent doses was low. After the second dose, tetravalent seroconversion 
TABLE 1. Partial listing of current dengue vaccine candidates in clinical development, with approach, developer, type of genes/antigens, and status

\begin{tabular}{|c|c|c|c|}
\hline Approach & Vaccine developer & $\mathrm{DEN}^{\mathrm{a}}$ genes or antigens & Status \\
\hline $\begin{array}{l}\text { Live, attenuated, produced on } \\
\text { PDK cells }{ }^{b}\end{array}$ & Mahidol/Sanofi Pasteur & All 10 DEN genes & $\begin{array}{l}\text { Phase } 2 \text { tetravalent, long-term } \\
\text { follow-up data up to eight } \\
\text { years }\end{array}$ \\
\hline $\begin{array}{l}\text { Live, attenuated, produced on } \\
\text { FRhL cells }{ }^{c}\end{array}$ & WRAIR/GSK Biologicals ${ }^{\mathrm{e}}$ & All 10 DEN genes & Phase $2 \mathrm{~b}$ tetravalent \\
\hline $\begin{array}{l}\text { Live, rationally attenuated with } 3 \text { ' } \\
\text { deletion mutation }\end{array}$ & $\begin{array}{l}\text { U.S. NIAID, }{ }^{f} \text { Johns Hopkins } \\
\text { University. }\end{array}$ & All 10 DEN genes & Phase 1-2 monovalent \\
\hline $\begin{array}{l}\text { Live, } 3 \text { ' deletion mutation, } \\
\text { DEN/DEN chimeric }\end{array}$ & $\begin{array}{l}\text { U.S. NIAID, Johns Hopkins } \\
\text { University. }\end{array}$ & 8 DEN4, 2 chimeric & Phase 1-2 monovalent \\
\hline $\begin{array}{l}\text { Live, rationally mutated with 3' } \\
\text { point mutations }\end{array}$ & U.S. FDA ${ }^{g}$ & $\begin{array}{l}\text { All } 10 \text { DEN genes (currently only } \\
\text { DEN2) }\end{array}$ & Preclinical (nonhuman primates) \\
\hline $\begin{array}{l}\text { Live, attenuated DENV-2 vector, } \\
\text { DEN/DEN chimeric }\end{array}$ & InViragen/Shanta & 8 DEN2, 2 chimeric & $\begin{array}{l}\text { Preclinical (nonhuman primates), } \\
\text { scheduled for human studies }\end{array}$ \\
\hline $\begin{array}{l}\text { Live, attenuated YF17D vector, } \\
\text { YFh/DEN chimeric }\end{array}$ & Acambis, Sanofi Pasteur & $\begin{array}{l}8 \text { YF genes, } 2 \text { chimeric DEN } \\
\text { genes }\end{array}$ & Phase 1-2 tetravalent \\
\hline $\begin{array}{l}\text { Subunit recombinant antigen, } \\
\text { adjuvanted }\end{array}$ & Hawaii Biotech & $2\left(80 \% \mathrm{E}^{\mathrm{i}}\right.$ and $\left.\mathrm{NS} 1^{\mathrm{j}}\right)$ & $\begin{array}{l}\text { Preclinical (nonhuman primates), } \\
\text { scheduled for human studies }\end{array}$ \\
\hline \multicolumn{4}{|c|}{$\begin{array}{l}\text { a DEN = candidate dengue vaccine virus. } \\
\text { b PDK cells = Primary dog kidney cells. } \\
\text { c FRhL cells = fetal rhesus lung cells. } \\
\text { d WRAIR = Walter Reed Army Institute of Research. } \\
\text { e GSK Biologicals = GlaxoSmithKline Biologicals. } \\
\text { f U.S. NIAID = United States National Institute of Allergy and Infectious Diseases. } \\
\text { g U.S. FDA = United States Food and Drug Administration. } \\
\text { h YF = yellow fever. } \\
\text { i } 80 \% E \text { = extracellular portion of the E protein. } \\
\text { i NS1 = nonstructural proteins of dengue viruses. }\end{array}$} \\
\hline
\end{tabular}

was $51 \%$ or $66 \%$, depending on the vaccine formulation, and between $85 \%$ and $100 \%$ after boosting (7). Detailed analysis revealed that DENV-3 was still underattenuated, and an attempt was made to molecularly rederive the strain in order to reduce reactogenicity. A plaque-purified strain was adapted to Vero cells (from African green monkey kidney epithelial cell lines) and thoroughly characterized preclinically to confirm commonly agreed phenotypic criteria of attenuation. A phase 1 study in flavivirus-naive adults surprisingly revealed unacceptably high reactogenicity. While this unexpected finding is being further investigated, and may point to an important role of innate immunity in the early response to dengue infection (8), the company (now Sanofi Pasteur) decided to put the further development of the live attenuated tetravalent vaccine on hold.

The Walter Reed Army Institute of Research (WRAIR) has, independently of the effort by Mahidol University, employed a similar strategy to de- velop a dengue vaccine. Human virulent DENV isolates were passaged on PDK cells for attenuation, and different passage levels were selected to assess attenuation, immunogenicity, and protective capacity in animal models. The vaccine is produced in fetal rhesus lung (FRhL) cells. While monovalent candidates proved safe and immunogenic in human studies, interference was observed once the candidate strains were combined into tetravalent formulations. For the purpose of empiric selection for high and balanced immunogenicity and low reactogenicity, 18 different tetravalent formulations have been compared in human volunteers (9).

In these clinical studies, conducted jointly by WRAIR and GlaxoSmithKline (GSK), formulation "17" was selected and used for a small safety and immunogenicity study in seven Thai schoolchildren. Following a two-dose regimen with sixmonth intervals, $100 \%$ tetravalent seroconversion was observed after two doses, combined with an acceptable reactogenicity profile. 
These results led to a randomized controlled trial, with a target age of 12-15 months, organized into escalating cohort sizes. Dose scheduling was the same as above, apart from one cohort receiving one-tenth of the dose. Safety and reactogenicity were good, and the reduced dose did not show a more favorable profile. However, immunogenicity assessment after the second dose revealed a strong cohort effect; tetravalent seroconversion was either above $90 \%$ or around $50 \%$, depending on the cohort, an observation requiring further investigation (10). The results also suggest that even in the absence of demonstrable antibody titers following primary immunization, successful priming might still have happened, as suggested by the effective response to the second dose. The manufacturer is not only pursuing the clinical development, but is also trying to further optimize the vaccine formulation.

\section{Live recombinant vaccines}

The ability to synthesize full-length cDNA of the flaviviral genomic RNA, to rederive RNA from transfected cells, and to derive infectious particles, when the resulting RNA is transfected into permissive Vero cells, has opened the possibility of producing genetically modified flaviviruses. This technology has been utilized by several laboratories, which have applied the following three different strategies to achieve virus attenuation: (1) the molecular attenuation of the dengue viruses by introducing selected mutations, (2) the insertion of dengue structural genes (prM/E) into the genetic backbone of a classically attenuated dengue strain, and (3) the insertion of $\mathrm{prM} / \mathrm{E}$ into the genetic backbone of the YF 17D vaccine strain, which serves as a vector.

Overall, the strategy of molecular attenuation of DENV is hampered by the lack of detailed understanding of molecular basis and determinants of virulence that could be specifically targeted for attenuation. Attenuation strategies have therefore focused on generic flaviviral noncoding elements that are believed to impact the ability of the virus to replicate. A group at the United States National Institutes of Health $(\mathrm{NIH})$ has produced a recombinant DENV that harbors a 30 nucleotide $(\Delta 30)$ deletion in the 3 ' noncoding region of the viral genome of each of the four dengue viruses. The candidate dengue (DEN) vaccine viruses developed by NIH involve the following two distinct approaches: (1) modifying the wild-type DEN1, DEN2, and DEN3 viruses into the previously described $\Delta 30$ dilution of the 3'-untranslated region of DEN4 virus (rDEN4 $\Delta 30)$, resulting in $\operatorname{rDEN} 1 \Delta 30, \operatorname{rDEN} 2 \Delta 30$, and rDEN3 330 viruses; and (2) constructing chimeric DEN1, DEN2, and DEN3/DEN4 viruses, expressing the $\mathrm{prM} / \mathrm{E}$ gene region of DEN1, DEN2, or DEN3 virus in the attenuated genetic background of the rDEN4 $\triangle 30$ virus (11). An interesting conceptual feature of these vaccine viruses is the fact that the $\mathrm{E}$ gene remains a wild-type genetic structure; this follows the concept of keeping high infectivity of the vaccine virus, which is believed to be encoded in the E gene, while attenuating the virus through its reduced capacity to replicate. DEN1 $\Delta 30$ and DEN4 30 have been tested as monovalent formulations in healthy adults at Johns Hopkins University (12). The candidates appear to be safe and immunogenic, but further genetic modifications are being considered to reduce some of the observed reactogenicity. Clinical trials with tetravalent formulations are being planned. The vaccine technology has been licensed to developing country vaccine manufacturers to produce and test candidate vaccines.

Researchers at the United States Food and Drug Administration (FDA) have approached molecular attenuation by introducing several mutations into the stem and loop structure at the terminus of the 3' untranslated region of the viral genome ("MutF"). A DENV-1 construct has been successfully tested in monkeys and awaits further evaluation in clinical trials (13).

Researchers at the United States Centers for Disease Control and Prevention (CDC) have developed another live recombinant chimeric tetravalent candidate vaccine, based on a classically attenuated DENV-2. It was shown that the DENV-2 strain 16681 PDK53 virus, from Mahidol University, carried attenuating mutations in its nonstructural genes (14), when prM/E genes of wild-type DENV$1,-3$, and -4 were cloned into nonstructural DENV2 , and the phenotypic markers of attenuation were retained. In collaboration with a commercial partner, the CDC has tested monotypic and tetravalent chimeric vaccines in cynomolgus monkeys. The results show good immunogenicity and low viremia, but some degree of interference when combined into a tetravalent formulation (10). The clinical testing of the candidates is being planned.

The development of a yellow fever/dengue virus chimeric vaccine candidate is being pursued by Acambis, in collaboration with Sanofi Pasteur. In this approach, the prM/E genes of wild-type dengue viruses replace the corresponding genes of the17D yellow fever vaccine. This vector platform, called ChimeriVax, is used for the development of other flavivirus vaccines; the most advanced vaccine candidate is a Japanese encephalitis vaccine. For the purpose of developing a tetravalent dengue vaccine, DENV-1-4 prM/E genes from human isolates were inserted into the vector. Extensive 
preclinical testing was done, including monkey neurovirulence, viremia, immunogenicity, and protection assays. Growth in hepatic cells and the potential for mosquito transmission was tested, and was found to be either similar or inferior to the parent YF17D vaccine $(15,16)$. Safety and efficacy of the tetravalent formulation were confirmed in nonhuman primates (17). Clinical trials started with testing the monovalent formulation ChimeriVaxDEN2, prior to assessing the tetravalent version. The vaccine was also tested in volunteers with preexisting vector (i.e., YF) immunity, and no interference on the level of the immune response could be demonstrated (18). Results showed high-titered responses and also very low and transient viremia. The tetravalent formulation was then administered to volunteers, using a two-dose schedule. Preliminary data analysis after dose one showed good immunogenicity, but only partial tetravalent seroconversion (10). Further analysis is expected, and a readjustment of the infective dose is being planned.

\section{Subunit and inactivated vaccines}

The most advanced subunit vaccine is being developed by Hawaii Biotech Inc., and is based on the envelope $(\mathrm{E})$ protein produced in the Drosophila S2 expression system, whereby glycosylation is maintained and immunoaffinity purified, in order to achieve conformational folding. The vaccine contains the extracellular portion of the E protein (called $80 \% \mathrm{E}$ ), plus the NS1 antigen, and is formulated in proprietary adjuvant. The rationale for including NS1 antigen was established in the suckling mouse protection model, and was confirmed when assessing the cell-mediated immune response in primates. Different antigen dose and adjuvant-type formulations were tested in rhesus macaques, and the antibody responses were assessed in response to four doses of vaccines. Very high titers were achieved with three doses, and the fourth dose did not show a boosting effect. Challenge studies were conducted using DENV-2 and DENV-4, demonstrating protection in some of the groups (10). The company anticipates the start of clinical studies in 2007.

Another approach towards the development of a subunit vaccine was chosen by the Center for Genetic Engineering and Biotechnology in Havana, Cuba. Structural subunits of the DEN E protein (domain III) were fused to the meningococcal P64k carrier protein and produced in a bacterial expression system for E. coli. DENV-2 candidates have been shown to induce protective immune responses in macaques, providing proof of concept that domain III is a protective epitope. Further studies will re- quire testing of tetravalent formulations in an adjuvant suitable for human use (19).

Several purified inactivated virus (PIV) vaccine formulations, based on DENV-2 and a multitude of adjuvants, have been tested in a comparative study conducted by WRAIR. Rhesus macaques received $5 \mu \mathrm{g}$ of DENV-2 PIV in formulation with one of five adjuvants, by intramuscular injection, at days zero and 90. Animals were challenged at day 160. All vaccines were nonreactogenic and stimulated neutralizing antibodies after one or two doses. Antibodies persisted to the day of challenge. Using conventional techniques, postchallenge viremia was not detected in several animals. However, viremia was measured in all animals using a TaqMan PCR, irrespective of the level of the prechallenge titer, except the control group immunized with live attenuated vaccine. In fact, there was no correlation between PRNT $_{50}$ titers and levels of viremia assayed by TaqMan. Only the live vaccine appeared to induce sterile immunity, as indicated by the lack of measurable anti-NS3 antibodies, in all three monkeys of the group (20).

The DNA vaccination approach has been applied to dengue; DNA shuffling and screening technologies have been used to construct DNA expression vectors encoding epitopes of all four serotypes (21). Shuffled tetravalent DNA vaccines elicit neutralizing antibody titers and confer partial protection when challenged with DENV-2. DNA has been delivered using a Biovector device (Biovector Therapeutics SA, France). Phase 1 clinical trials with monovalent DNA vaccines are scheduled.

\section{PROSPECTS AND PROBLEMS}

In summary, the dengue vaccine pipeline appears sufficiently advanced and diverse. Therefore, the first dengue vaccine could be licensed within the next five years. The pipeline contains a majority of live attenuated candidate vaccines, building on the successes of other live flavivirus vaccines, especially the yellow fever vaccine. A theoretical advantage of live attenuated viral vaccines is their track record of producing lasting antibody responses and protection. Also, the cost of production of live vaccines should be less than other vaccine technologies.

Candidate vaccines will soon be evaluated in population-based efficacy trials in exposed populations, requiring a number of technical, operational, and regulatory issues to be addressed. Dengue vaccines will need to be evaluated against changing patterns of transmission intensity and circulating dengue viruses, as well as other circulating flaviviruses. Therefore, multicentric vaccine trials may be warranted in different geographic settings, in- 
cluding Asia and the Americas. Vaccine developers as well as the Pediatric Dengue Vaccine Initiative (PDVI) (22) are in the process of establishing field sites suitable for such trials, with highly characterized flavivirus epidemiology,

Clinical endpoints need to be defined for dengue vaccine efficacy trials. While from a public health perspective the prevention of severe dengue disease will be a priority indication, vaccine developers may opt for prevention of other, more frequent manifestations of dengue disease, in order to keep the sample size of the study reasonable. Protection of severe disease may be considered as a secondary endpoint. The World Health Organization Initiative for Vaccine Research (WHO/IVR) has set up a study group to address this and other considerations for the planning of efficacy trials, in order to provide guidance for population-based trials. This will also include directions for safety assessment of dengue vaccines.

There is currently no established immunological correlate for protection from dengue, even though there is strong evidence that points to the protective role of neutralizing antibodies (23). The availability of a correlate would greatly facilitate the evaluation of candidate vaccines, and $\mathrm{WHO}$ has recommended comprehensive immunologic studies to be done, in conjunction with future trials, for the definition of correlates. In that context, there is also the need for harmonization and validation of key immunological assays, especially for the assessment of functional, neutralizing antibodies. WHO, in collaboration with PDVI, is developing tools and reagents for that purpose. PDVI is also investing in the fine characterization of antibody responses, with the aim of distinguishing neutralizing from potentially enhancing biological features. Such a tool would be of great value to the characterization of candidate vaccines, but would not replace longterm safety follow-up.

\section{Public health implications}

Although the systematic introduction of dengue vaccines for public health use may be years ahead, there is still a need to develop a better understanding of the disease epidemiology, including age-specific incidence rates in endemic countries. Vaccination strategies will need to be developed based on not only the characteristics of the vaccine, but also the epidemiology of dengue. As morbidity from dengue is straining the health care systems of endemic countries, there is also a great need for health economic studies, especially cost-of-illness and cost-effectiveness studies.
The global importance of dengue, including increased severity and endemicity of the disease, combined with new funding mechanisms for developing a vaccine, have triggered renewed interest and investment into dengue vaccine research. The application of novel technologies for the development of these vaccines is showing promise.

Acknowledgements. The author is indebted to A. Barrett (University of Texas Medical Branch at Galveston), M.G. Guzmán (Instituto Pedro Kourí, Habana, Cuba), and D. Vaughn (GlaxoSmithKline) for critical reading of the manuscript.

Disclaimer. This report contains the individual views of the author, and does not necessarily represent the decisions or the stated policies of the World Health Organization.

\section{SINOPSIS}

\section{Vacunas contra el dengue: una revisión de las vacunas candidatas en etapas avanzadas de desarrollo}

Los esfuerzos sistemáticos para desarrollar una vacuna contra el dengue comenzaron durante la Segunda Guerra Mundial, inspirados en el desarrollo exitoso de una vacuna contra la fiebre amarilla. Sin embargo, la falta de modelos adecuados de la enfermedad, la información incompleta acerca de los mecanismos patogénicos y los insuficientes incentivos económicos han dificultado los avances. Debido al impacto actual del dengue en todo el mundo y su explosiva diseminación, ha aumentado el interés en el desarrollo de vacunas contra el dengue y se ha avanzado considerablemente en el camino hacia la evaluación clínica de vacunas candidatas. La Iniciativa para la Investigación en Vacunas, de la Organización Mundial de la Salud, está facilitando el desarrollo de y los ensayos con las vacunas candidatas. Las vacunas contra el dengue que se encuentran actualmente en etapas avanzadas de desarrollo son de tres tipos fundamentales: 1) vivas atenuadas; 2) vivas recombinantes; $y$ 3) de subunidades e inactivadas. La mayoría de las vacunas en cartera son vivas atenuadas, siguiendo el camino exitoso de otras vacunas vivas contra flavivirus, especialmente de la desarrollada contra la fiebre amarilla. En general, las vacunas contra el dengue que se encuentran actualmente en desarrollo están bastante avanzadas y son muy diversas. Muy pronto comenzará la evaluación de estas vacuna candidatas en ensayos de eficacia basados en poblaciones expuestas, lo que requerirá resolver varios problemas técnicos, operacionales y regulatorios.

Palabras clave: dengue, Aedes, Flavivirus, fiebre dengue hemorrágica, vacunas virales. 


\section{REFERENCES}

1. World Health Organization. WHO/ WPRO/SEARO meeting on DengueNet implementation in South-east Asia and the Western Pacific, Kuala Lumpur, 11-13 December 2004. Wkly Epidemiol Rec. 2004;79(6):57-62.

2. Clark DV, Mammen MP Jr., Nisalak A, Puthimethee V, Endy TP. Economic impact of dengue fever/dengue hemorrhagic fever in Thailand at the family and population levels. Am J Trop Med Hyg. 2005;72(6):786-91.

3. Halstead SB. Pathogenesis of dengue: challenges to molecular biology. Science. 1988;239(4839):476-81.

4. Halstead SB, Shotwell H, Casals J. Studies on the pathogenesis of dengue infection in monkeys. I. Clinical, laboratory responses to primary infection. J Infect Dis. 1973;128(1):7-14.

5. Rothman AL. Immunology and immunopathogenesis of dengue disease. Adv Virus Res. 2003;60:397-419.

6. Bhamarapravati N, Sutee Y. Live attenuated tetravalent dengue vaccine. Vaccine. 2000;18(suppl 2):44-7.

7. Sabchareon A, Lang J, Chanthavanich $P$, Yoksan S, Forrat R, Attanath $\mathrm{P}$, et al. Safety and immunogenicity of a three dose regimen of two tetravalent live-attenuated dengue vaccines in five- to twelve-year-old Thai children. Pediatr Infect Dis J. 2004;23(2):99-109.

8. Sanchez V, Gimenez S, Tomlinson B, Chan PK, Thomas GN, Forrat R, et al. Innate and adaptive cellular immunity in flavivirus-naive human recipients of a live-attenuated dengue serotype 3 vaccine produced in Vero cells (VDV3). Vaccine. 2006;24(23):4914-26.

9. Edelman R, Wasserman SS, Bodison SA, Putnak RJ, Eckels KH, Tang D, et al. Phase I trial of 16 formulations of a tetravalent live-attenuated dengue vaccine. Am J Trop Med Hyg. 2003;69(6 Suppl):48-60.
10. World Health Organization, Department of Immunization, Vaccines and Biologicals. Report of the meeting of the WHO Task Force on Clinical Trials of Dengue Vaccine. Geneva: WHO; 2006. (WHO/ IVB/06.10). Available from: http:// www.who.int/vaccines-documents / Accessed 10 April 2007.

11. Blaney JE Jr., Durbin AP, Murphy BR, Whitehead SS. Development of a live attenuated dengue virus vaccine using reverse genetics. Viral Immunol. 2006; 19(1):10-32.

12. Durbin AP, Whitehead SS, McArthur J, Perreault JR, Blaney JE Jr., Thumar B, et al. rDEN4delta30, a live attenuated dengue virus type 4 vaccine candidate, is safe, immunogenic, and highly infectious in healthy adult volunteers. J Infect Dis. 2005;191(5):710-18.

13. Markoff L, Pang X, Houng HS, Falgout $\mathrm{B}$, Olsen R, Jones E, et al. Derivation and characterization of a dengue type 1 host range-restricted mutant virus that is attenuated and highly immunogenic in monkeys. J Virol. 2002;76(7):3318-28.

14. Huang CY, Butrapet $S$, Tsuchiya KR, Bhamarapravati N, Gubler DJ, Kinney RM. Dengue 2 PDK-53 virus as a chimeric carrier for tetravalent dengue vaccine development. J Virol. 2003;77(21): 11436-47.

15. Brandler S, Brown N, Ermak TH Mitchell F, Parsons M, Zhang Z, et al. Replication of chimeric yellow fever virus-dengue serotype $1-4$ virus vaccine strains in dendritic and hepatic cells. Am J Trop Med Hyg. 2005;72(1):74-81.

16. Higgs $S$, Vanlandingham DL, Klingler KA, McElroy KL, McGee CE, Harrington $\mathrm{L}$, et al. Growth characteristics of ChimeriVax-Den vaccine viruses in Aedes aegypti and Aedes albopictus from Thailand. Am J Trop Med Hyg. 2006; 75(5):986-93.
17. Guirakhoo F, Pugachev K, Zhang Z, Myers G, Levenbook I, Draper K, et al. Safety and efficacy of chimeric yellow fever-dengue virus tetravalent vaccine formulations in nonhuman primates. J Virol. 2004;78(9):4761-75.

18. Guirakhoo F, Kitchener S, Morrison D, Forrat R, McCarthy K, Nichols R, et al. Live attenuated chimeric yellow fever dengue type 2 (ChimeriVax-DEN2) vaccine: phase I clinical trial for safety and immunogenicity: effect of yellow fever pre-immunity in induction of cross neutralizing antibody responses to all 4 dengue serotypes. Hum Vaccin. 2006; 2(2):60-7.

19. Hermida L, Bernardo L, Martin J, Alvarez M, Prado I, Lopez C, et al. A recombinant fusion protein containing the domain III of the dengue- 2 envelope protein is immunogenic and protective in nonhuman primates. Vaccine. 2006; 24(16):3165-71.

20. Putnak JR, Coller BA, Voss G, Vaughn DW, Clements D, Peters I, et al. An evaluation of dengue type-2 inactivated, recombinant subunit, and live-attenuated vaccine candidates in the rhesus macaque model. Vaccine. 2005;23(35):4442-52.

21. Raviprakash $\mathrm{K}$, Apt D, Brinkman A Skinner C, Yang S, Dawes G, et al. A chimeric tetravalent dengue DNA vaccine elicits neutralizing antibody to all four virus serotypes in rhesus macaques. Virology. 2006;353(1):166-73.

22. International Vaccine Institute. Pediatric Dengue Vaccine Initiative [Internet site]. Available from: http:/ /www.pdvi.org/. Accessed 10 April 2007.

23. Hombach, J, Cardosa JM, Sabchareon A, Vaughn DW, Barrett AD. Scientific consultation on immunological correlates of protection induced by dengue vaccines. Report from a meeting held at the World Health Organization 17-18 November 2005. Vaccine. Forthcoming 2007. 